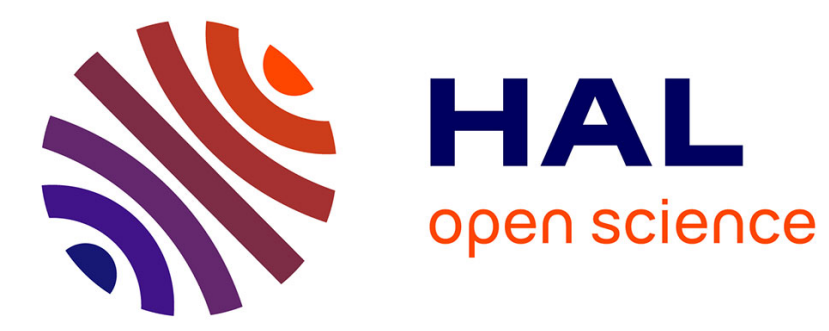

\title{
XUV LASERS - A SURVEY OF PROGRESS
}

M. Key

\section{To cite this version:}

M. Key. XUV LASERS - A SURVEY OF PROGRESS. Journal de Physique Colloques, 1988, 49 (C1), pp.C1-135-C1-144. 10.1051/jphyscol:1988129 • jpa-00227449

\section{HAL Id: jpa-00227449 https://hal.science/jpa-00227449}

Submitted on 1 Jan 1988

HAL is a multi-disciplinary open access archive for the deposit and dissemination of scientific research documents, whether they are published or not. The documents may come from teaching and research institutions in France or abroad, or from public or private research centers.
L'archive ouverte pluridisciplinaire HAL, est destinée au dépôt et à la diffusion de documents scientifiques de niveau recherche, publiés ou non, émanant des établissements d'enseignement et de recherche français ou étrangers, des laboratoires publics ou privés. 


\title{
XUV LASERS - A SURVEY OF PROGRESS
}

\author{
M.H. KEY \\ SERC Rutherford Appleton Laboratory, Chilton, \\ GB-Didcot oX11 oQX, Great-Britain
}

RESUME

Le développment des lasers a rayonnement XUV est tellement avancé depuis $1985 \mathrm{qu}$ 'on peut parler d'une famille nouvelle de lasers dont la dureé d'impulsion est courte et la puissance est grande. Les characteristiques actuelles et potentielles de ces lasers et les resultats les plus importants sont presentés.

\section{ABSTRACT}

There has been an upsurge recently of both progress and interest in the development of XUV and X-ray lasers to such an extent that it is now possible to envisage the systematic development and application of a new family of powerful pulsed XUV lasers. The potential and actual characteristics of these lasers and the highlights of recent work will be reviewed.

\section{Introduction}

The physical concepts leading to XUV laser action in Iaser produced plasmas have been known for many years but detailed solutions to the practical and theoretical problems of demonstrating XUV lasers have been found only recently with the use of multiterawatt laser systems backed up by sophisticated computer modelling. Recent reviews detail the background and this paper sets out the main features of the sudden upsurge of progress in the last few years $(1)$.

A basic characteristic of any plasma laser is the scaling with frequency of fluorescent,power density and therefore of pumping power density. This shows a $v^{4.5}$ increase which imposes a requirement of immense fluorescent brightness for XUV lasers. With laser produced plasmas giving the most intense laboratory XUV brightness as shown in figure 1, it is not surprising to find them as the first XUV laser media, nor to find these lasers operating at the $X$-ray conversion efficiency peaks of ions with residual $K L$ and $M$ shell electrons ${ }^{2}$.

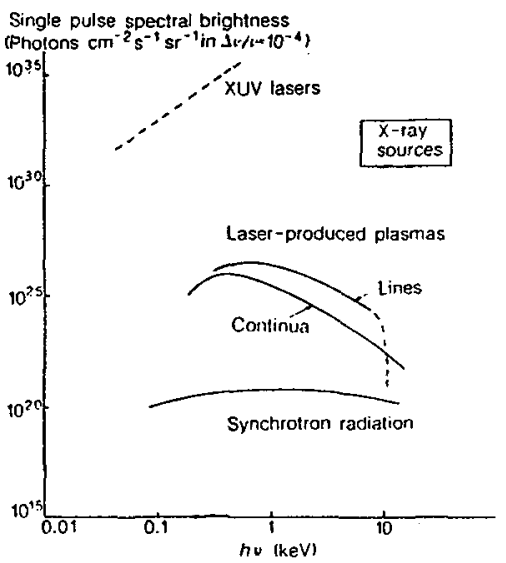

Fig. 1 Comparison of the absolute spectral brightness of XUV and $X$-ray sources. (Syndrotron data are from the SERC Syndrotron Radiation Source (SRS) and laser-produced plasma data are compiled for $10^{12}$ watt $\mathrm{Nd}$ glass lasers.) 
Experiments have involved the use of line foci to create elongated cylindrical plasmas of small diameter from fibres, thin foils and solid targets as shown in figure 2. The amplification of spontaneous emission in a single transit along the plasma column gives an exponentially increasing intensity with increasing length which can be observed, for small exponents $g l$, in the axial/transverse intensity ratio

$(\exp (g l)-1) / g l$ and for larger values of $g l$ in the obvious exponentiation with length. For $g l \geq 8$ the ASE has a narrow beam angle and for $g l>15$ saturation occurs with stimulated emission becoming more probable than spontaneous emission, ie a saturated ASE laser.

The characteristics of a saturated single transit ASE ${ }^{(1)}$ laser of beam aperture $W$ and lengt:h $I$ include high power and power density P/lMWatt $\sim\left(W^{2} / 10^{-4} \mathrm{~cm}^{2}\right)(h v / 1 M W)^{4} .5$, narrow bandwith $\Delta v / v \sim 2 \times 10^{-5}$, coherence length $500 \mu \mathrm{m} \times(\lambda / 10 \mathrm{~mm})$, spatial coherence distance $\mathrm{W} / \mathrm{n}$ (where $n=W^{2} / L \lambda \sim 50$ ) and beam divergence $W / L \sim 10^{-2}$ to $10^{-3} \mathrm{rad}$. The spectral brightness is extreme and, as indicated in figure 1 , exceeds by many orders of magni.tude to that of any other source.

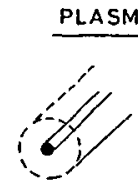

Fibre

\section{XUV LASERS (A.S.E.)}

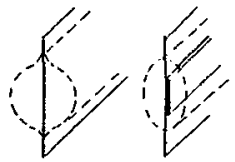

Thin Foil Ribbon

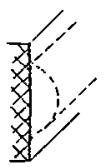

Solid

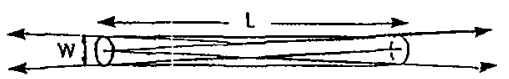

Fig 2

\section{Ne-Iike $3 p-3 s$}

A major breakthrough in XUV lasers was a 1985 experiment using the world's most powerful laser (NOVA in the USA) which showed laser gain on $3 \mathrm{p}-3 \mathrm{~s}$ transitions of $\mathrm{Ne}-1$ ike $\mathrm{Se} \mathrm{XXV}^{(3)}$. The mechanism is illustrated in figure 3 and relies on strong $3 s-2 p$ resonance emission to depopulate the $3 \mathrm{~s}$ level. The $3 \mathrm{p}$ levels are populated both by collisional (monopole) excitation from $2 p$ to $3 p$, by dielectronic recombination and by cascading from higher levels and have no allowed radiative decay to $2 \mathrm{p}$. The temperature should be as high as possible to maximise collisional excitation without ionising the Ne-like ions and the density as high as possible but below the collisional thermalisation limit of the $3 \mathrm{~s}$ and $3 \mathrm{p}$ levels (ie. LTE limit above $\mathrm{n}=3$ ).

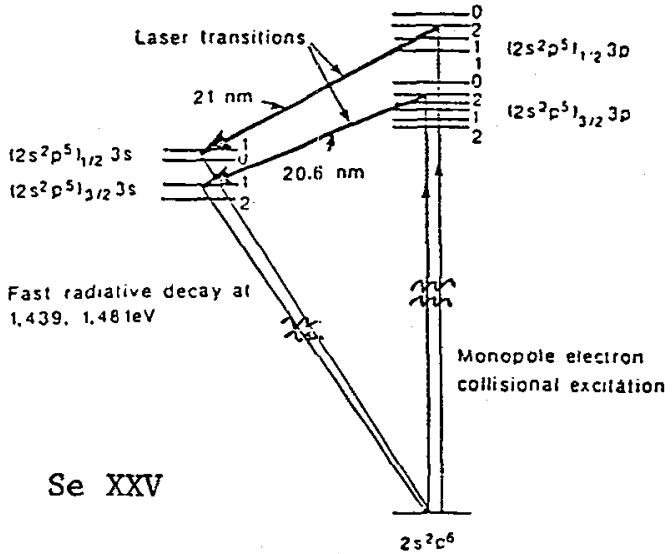

Fig 3

The best conditions are $\mathrm{kT}=1000 \mathrm{eV}$ and $\mathrm{n}_{e} \sim 5 \times 10^{20} \mathrm{~cm}^{-3}$ and the plasma must be small enough in lateral dimensions for resonance emission to escape without reabsorption. Both requirements have been achieved 
with a thin film target ( $750 \AA$ of se on $1500 \AA$ of polymer) irradiated in a $200 \mu \mathrm{m}$ wide line focus with $10^{12} \mathrm{Wcm}^{-1}$ in a $500 \mathrm{psec}$ pulse of $0.53 \mu \mathrm{m}$. A gain coefficient of $4 \mathrm{~cm}^{-1}$ on $\mathrm{J}=2$ to 1 transitions at $206 \AA-209 \AA$ has been observed with a maximum gain $x$ length gl $\sim 14$ giving $10^{6}$ single

transit amplification! The output power is $10^{6} \mathrm{~W}$ in a $200 \mathrm{psec}$ pulse and the beam divergence $20 \mathrm{mrad}$. Refraction in the plasma begins to be a problem at the long $(5 \mathrm{~cm})$ length with the beam being deflected out of the region of gain ${ }^{(4)}$.

Isoelectronic scaling to Mo XXXIII has been demonstrated ${ }^{(4)}(5)$ with $2 \times 10^{12} \mathrm{Wcm}^{-1}$ pumping and laser amplification at $g l$ up to 7 on transitions in the range 106-140 \& (figure 4).

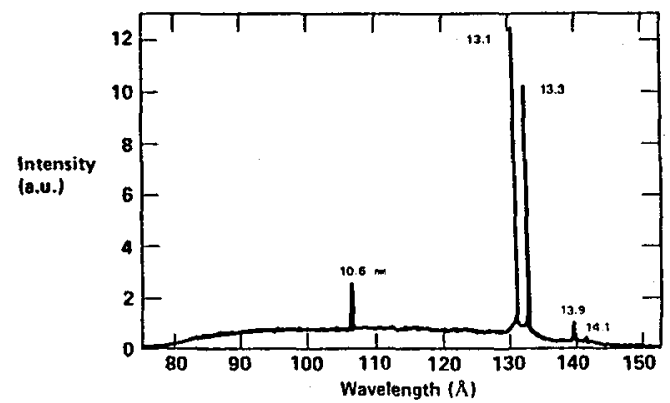

Fig 4

Ne-like Mo spectrum for an amplifier length of $1.7 \mathrm{~cm}$

Extrapolation to still shorter wavelength with the $3 p-3$ s scheme is unpromising because of the rapidly falling ( $g l / p u m p$ power) summarised in figure 5. The underlying reason for this is illustrated in figure 6 which shows the small $3 \mathrm{p}-3 \mathrm{~s}$ splitting relative to $2 \mathrm{p}-3 \mathrm{p}$ excitation energy in the Ne-like scheme.

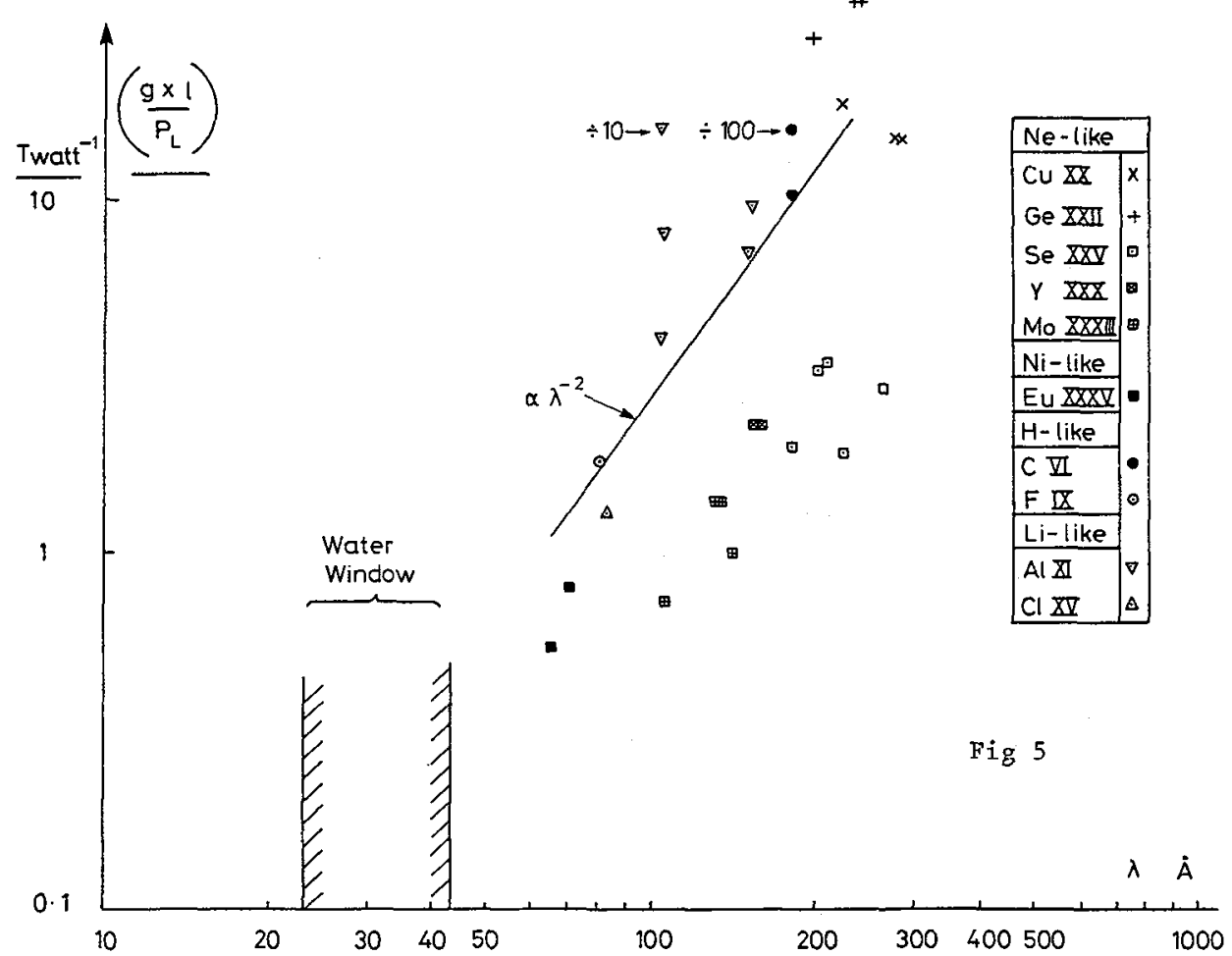


A considerable increase in $g l / P$ has been achieved with 2 nsec $1.06 \mu \mathrm{m}$ pump pulses and both solid and thin foil targets for transitions in $\mathrm{Cu} \mathrm{XX}$ and Ge XXII as shown in figure 5, though the reason for the better performance in these, experiments with $\mathrm{gl}$ up to 6 and $\mathrm{g}$ up to $4 \mathrm{~cm}^{-1}$ is not yet understood $(6)$.

\section{Ni-like $4 d-4 p$}

Further progress to shorter wavelength has been achieved with an analogous scheme using $4 \mathrm{~d}-4 \mathrm{p}$ transitions in Ni-like ions $(7)$. The $3 \mathrm{~d}^{10}$ closed shell of the Ni-like ion is very stable and the excitation energy of the $4 d$ level is significantly smaller relative to the $4 d-4 p$ transition energy than in the analogous Ne-like scheme, as shown in figure 6. Ni-like Eu XXXVI has given $g l \imath 1.5 \mathrm{~cm}^{-1}$ and $g l \leq 3$ at 66 and $71 \AA$ as shown in figure 7 , with 2 Twatt $\mathrm{cm}^{-1}$ pump power. Unpublished reports indicate successful isoelectronic extrapolation to $\mathrm{Yb} X X X X$ at 51 $\AA$ which is presently the shortest reported wavelength of laser amplification. The scheme clearly has some prospects for laser action in the water window using higher $Z$ elements albeit requiring very high pump power as shown in figure 5 .
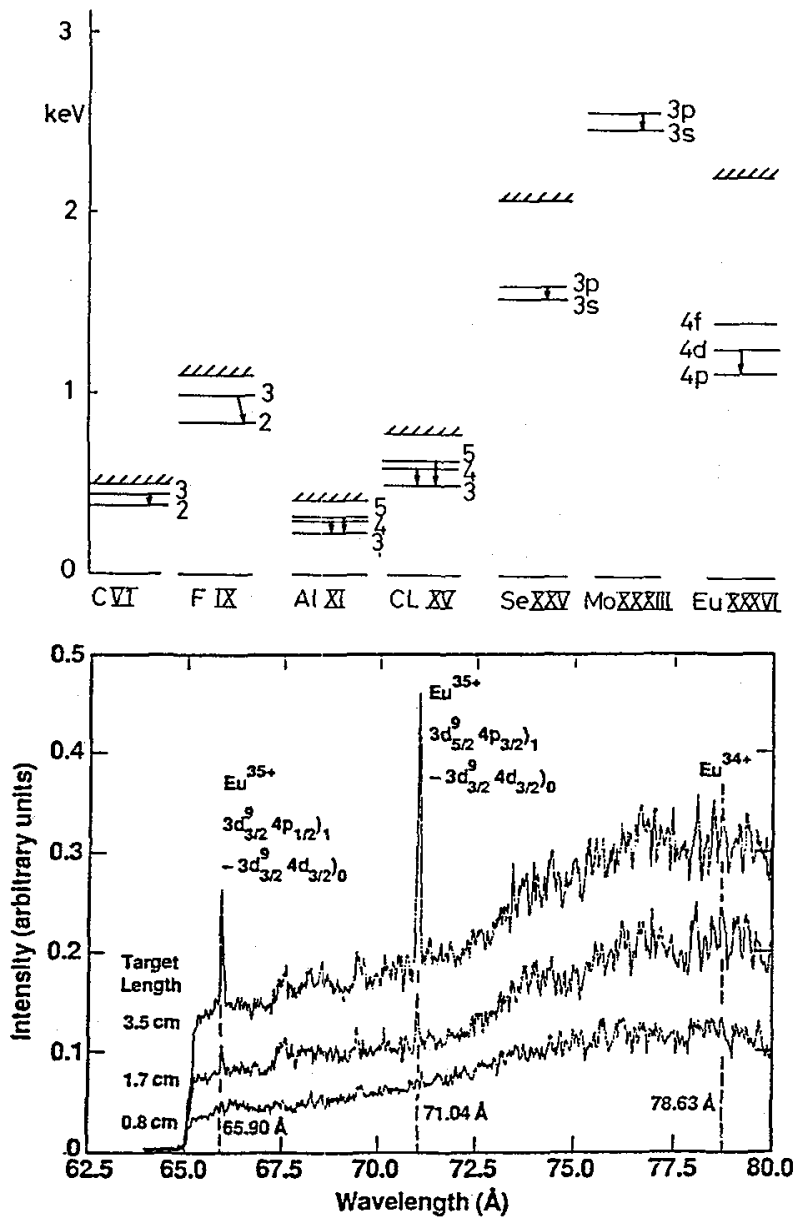

Fig 7

\section{H-like recombination}

A quite different class of XUV lasers is based on transient production of population inversion in a rapidly recombining plasma. The initial state is a hot fully ionised plasma of bare nuclei and free electrons at high density produced by short duration laser pulse irradiation. 
The rot surface layer of plasma explodes to form an expanding cylinder of plasma (see figure 8) and cools adiabatically to a density at which the LTE limit is at about $n=3$ and the levels above $n=3$ are in Saha Boltzmann equilibrium with the cool free electrons. The equilibriation above $\mathrm{n}=2$ is very rapid and there is no time lag relative to the cooling process. The $n=2$ level has a lower than LTE population and is depopulated by Lya radiative decay, for a sufficiently small cylindrical plasma with a strong radial velocity gradient giving a Doppler shift decoupling of the reabsorption of the Lya transition in inner and outer regions. The $n=1$ level is populated well below the equilibrium level because of the rather slow processes of recombination to $n=1$. Population inversion and gain is thus established for the 3-2 Balmer $\alpha$ transition.

\section{CZ RECOMBINATION LASER}
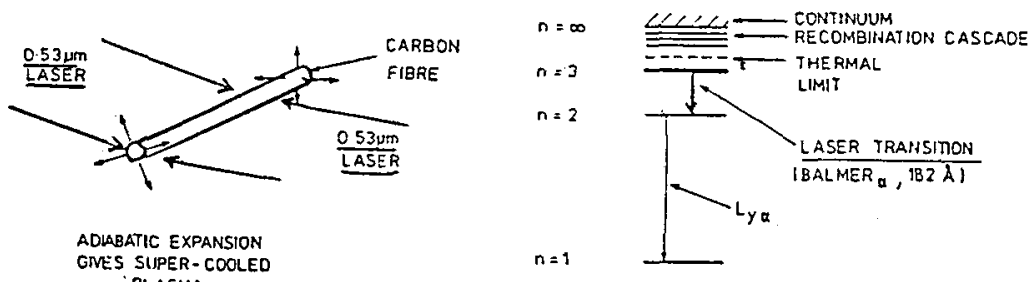

ADLABATIC EXPANSION

GNES SUPER - COOLED

PLASMA

Fig 8

This scheme has been studied in detail for C VI by numerical and analytical modelling $(8)$, illustrated in figure 9 and leading to the conclusion that optimum conditions are obtained with a laser irradiated carbon fibre target in which the initial plasma is at $10^{21} \mathrm{~cm}^{-3}$ and $200 \mathrm{eV}$, requiring $70 \mathrm{psec}$ pulse irradiation of a 7 m dianeter fibre at 0.3 TWatt $\mathrm{cm}_{-3}^{-1}$ : The plasma expands to reach $30 \mathrm{eV}$ at density of $2 \times 10^{19} \mathrm{~cm}^{-3}$ in less than $1 \mathrm{nsec}$ when significant gain ( $10 \mathrm{~cm}^{-1}$ ) is predicted.

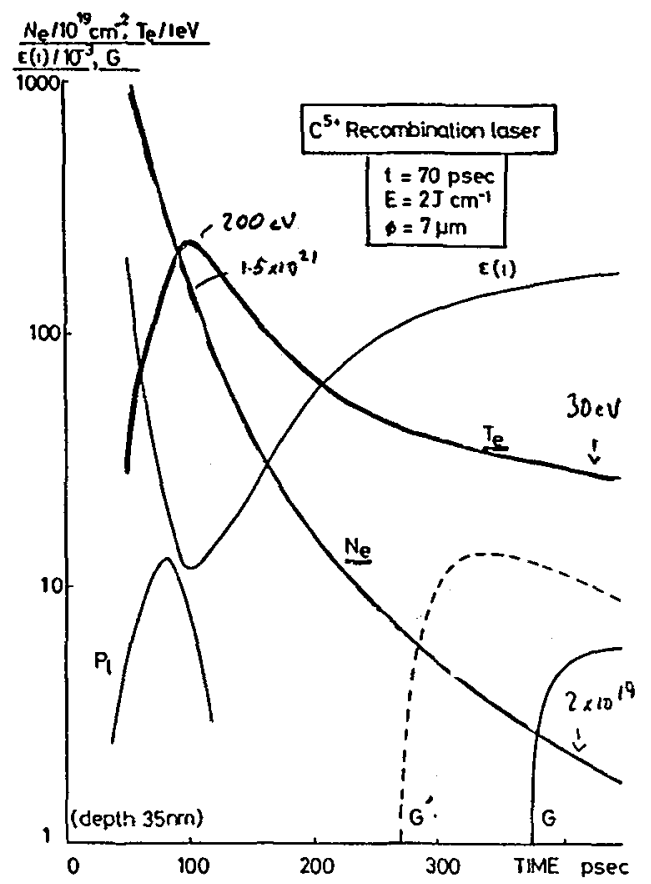

Fig 9

Computed time variation of plasma parameters. and gain. 
A novel optical system producing aberration free line foci in a six beam configuration for irradiation of fibre targets has been developed ${ }^{(9)}$, together with a new diagnostic system based on time resolved XUV spectrometers having a streak camera coupled to an aperiodic grazing incidence diffraction grating which disperses the spectrup into a perpendicular flat field instead of the usual Rowland circle ${ }^{(10)}$. Gain of $4 \mathrm{~cm}^{-1}$ for length up to $1 \mathrm{~cm}$ giving $50 \mathrm{x}$ single transit amplification has been recorded for C VI H $\alpha$ at 182 with a carbon fibre irradiated as specified earlier (figure 10) (11).

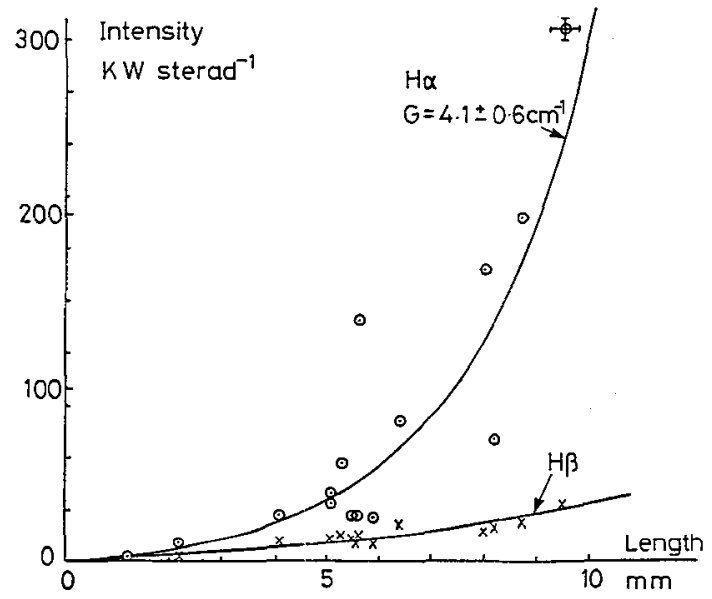

Fig 10 Variation of intensity with length for $C$ VI $H_{\alpha}$ and $H_{B}$

Isoelectronic scaling has also been investigated ${ }^{(2)}$ and modelling has shown a pump power requirement scaling as $\mathrm{Z}^{4}$ with gain produced at higher final density scaling as $Z$ for which the LTE limit is around $n=3$. A problem arises in that the initial plasma heating is at the fixed critical density whereas ideally it would also be at a density increasing as $z^{7}$. This imposes $a$ limit at which the density required for laser action is too close to the initial density to allow adequate adiabatic cooling.

Detailed calculations confirmed that the mechanism operates satisfactorily for $F$ IX at $81 \&$ and a successful experiment gave the then shortest wavelength of laser action prior to the recent results with Ni-like ions.

Figure 11 illustrates a streaked spectrum (13) showing intense axial

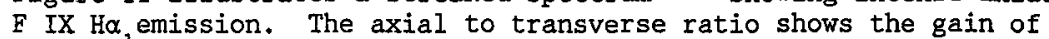
$5.5 \mathrm{~cm}^{-1}$ for 1.7 Twatt/cm pumping (and absorption at lower pumping) in figure 12. The duration of the gain has been measured as $\sim 0.5$ nsec.

An interesting feature of the recombination scheme in general is its better efficiency in terms of $g l / P$ shown in figure 5. Fibre targets absorb only $10 \%$ of the incident power and the efficiency could therefore in principle be made higher with improved coupling. 

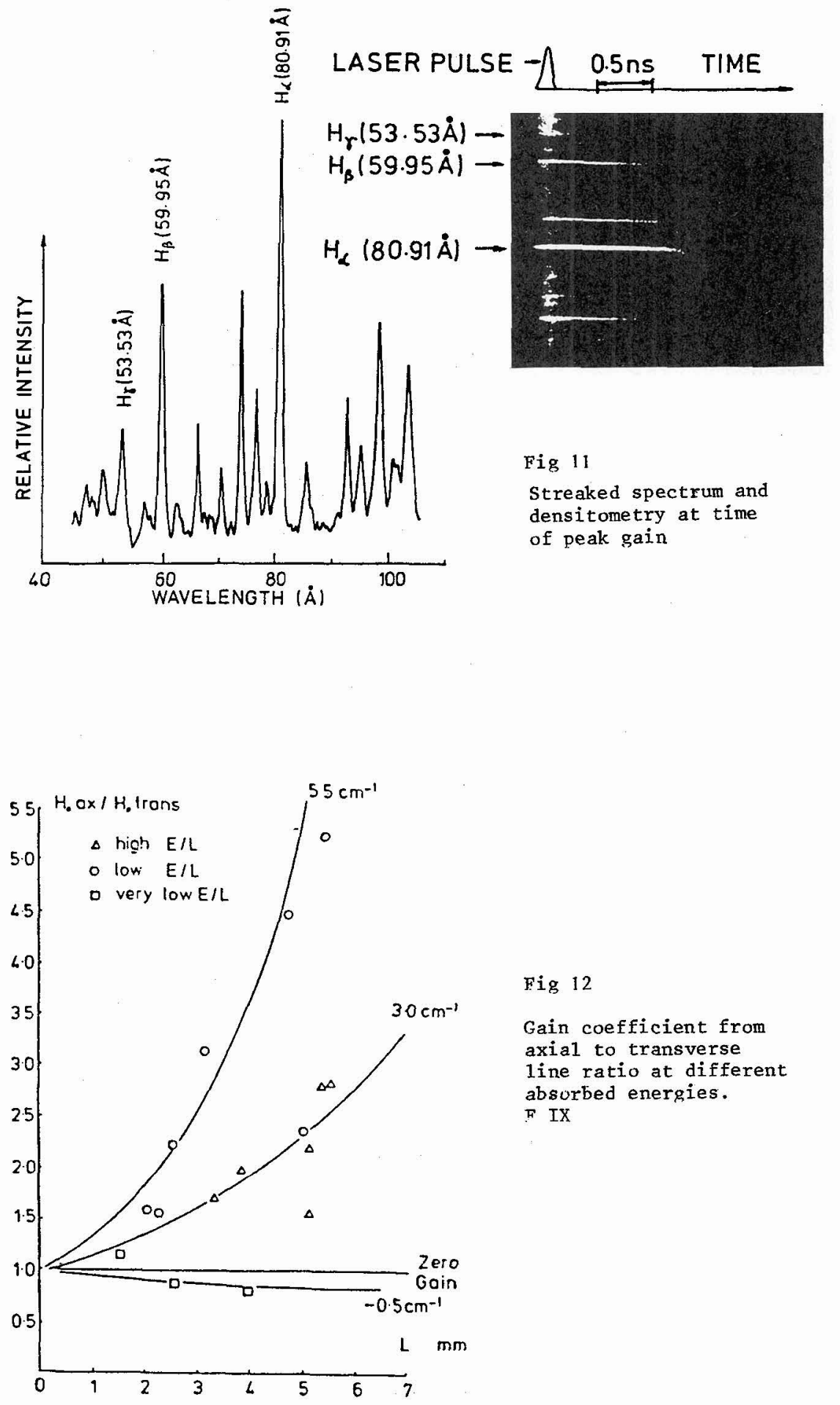

Fig 12

Gain coeficient from axial to transverse

line ratio at different

absurbed energies.

F IX 
A dramatically higher $g l / P$ has been seen for $C$ VI Ho laser action in a magnetically confined laser produced plasma with gl $\sim 6(14)$. The cylindrical plasma is produced by a $4 \times 10^{9} \mathrm{~W}, 10.6 \mu \mathrm{m} \mathrm{CO} 2$ laser pulse of $75 \mathrm{nsec}$ duration focussed to a spot on a solid $\mathrm{C}$ target. An axial field of 9 Tesla confines the plasma flow to a narrow cylinder almost $1 \mathrm{~cm}$ long in which gain is produced in a cool boundary layer. The mechanism is not well understood and not readily scaled to shorter wavelength but the $g \ell / P$ is almost $1000 \mathrm{x}$ better than the other schemes illustrated in figure 5 and the long pulse duration favours the use of a resonator as discussed later.

\section{Li-like recombination}

The efficiency advantage of $\mathrm{H}$-like recombination arises from the more favourable ratio of laser transition energy to ionisation energy of the laser ion and the situation is slightly more favourable again for recombination from the next lower stable ion configuration (He-like) to Li-like, as shown in figure 6 .

This fact has been exploited in experiments with Al XI in which gain was initially observed on the 103/106 \& 5f-3d transitions using a $6 \times 10^{9} \mathrm{~W}, 1 \mathrm{~m} 20 \mathrm{nsec}$ pump laser, to irradiate a solid al target (15). gl values were low ( 2 ) and the gain coefficient was $52 \mathrm{~cm}^{-1}$ but the $\mathrm{gl} / \mathrm{P}$ was very high (see figures 5 and 13 ). Isoelectronic scaing to $\mathrm{S}$ XIII has been examined and gain on the $5 f-3 d$ trnasition at $65.2 \&$ has been inferred indirectly $(16)$.

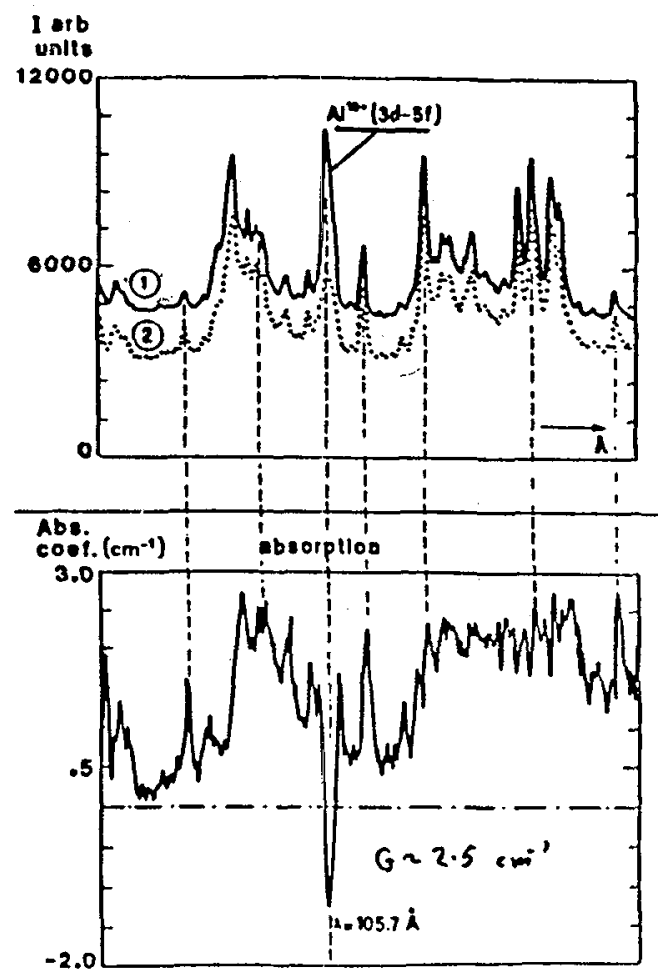

(1) $L .7 .1 \mathrm{~mm}$

(2) $1.41 \mathrm{~mm}$

Fig $1 \cdot 3$

Axial spectra for 2 lengths and gain deduced from intensity ratios.

The scheme has also recently been tried with fibre targets for which the smaller plasma mass reduces optical trapping of the resonance radiation which depopulate the lower laser level. Higher gain $23 \mathrm{~cm}^{-1}$ was observed on both the $5 \mathrm{f}-3 \mathrm{~d}$ and $4 \mathrm{f}-3 \mathrm{~d}$ transitions, the latter at $154 \AA^{(17)}$, see Fig 14. The high gain of $5 \mathrm{f}-3 \mathrm{~d}$ relative to $4 \mathrm{f}-3 \mathrm{~d}$ is unexplained at present. 


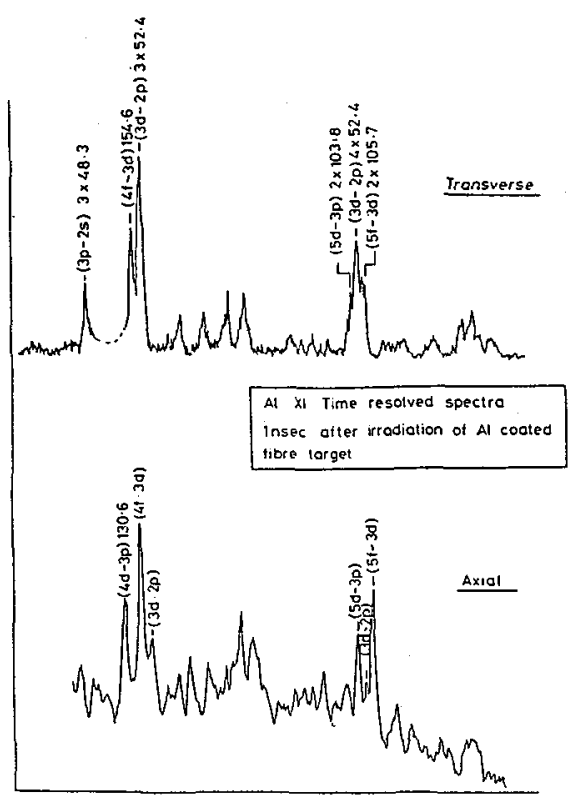

Fig 14

Isoelectronic scaling has been demonstrated with $\mathrm{g} \sim 3 \mathrm{~cm}^{-1}$ gain observed at $83 \AA$ on the $4 \mathrm{f}-3 \mathrm{~d}$ transition of $\mathrm{Cl} X V$ at a pump power level of $1.5 \mathrm{TW} \mathrm{cm}^{-1}$ in $70 \mathrm{psec}$ pulses using $\mathrm{NaCl}$ coated $7 \mu \mathrm{m}$ fibre targets $(18)$.

The possibility of a further class of recombination laser using recombination from the stable Neon-like form to Na-like is currently under study with interest in the $5 \mathrm{~g}-4 \mathrm{f}$ transition $(19)$.

\section{Future Developments}

The future prospects for XUV laser research are exciting with expectation of laser action in the 'water window' soon, which will open up biological applications. Early work is already underway to develop resonators using the new XUV multilayer optics $(4)$ and the first demonstration of laser produced XUV holograms has been made opening up the area of holography $(20)$.

\section{X-Ray Holography (With Full Reconstruction) Using the Ne-like Se XRL Has Been Demonstrated}

迠

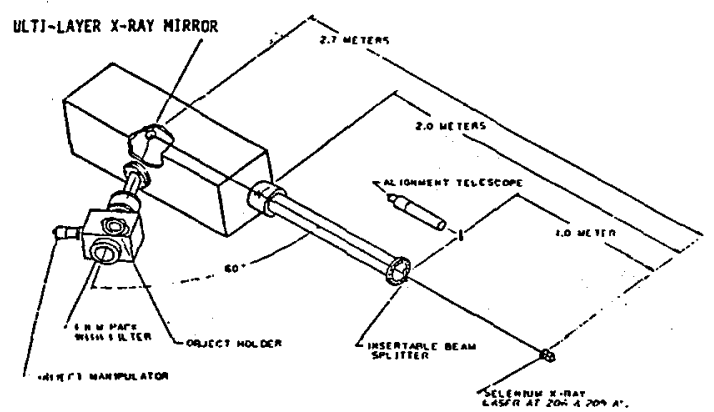

Experimental Setup (Gabor Geometry)

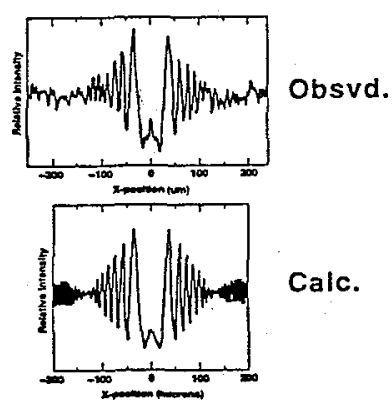

Fig 15

( $8 \mu$ Wire) 


\section{Acknowledgments}

My review of this topic of XUV lasers is based on information from my colleagues from UK Universities and at the Rutherford Appleton Laboratory collaborating in the study of XUV lasers as well as on material supplied by others in research programmes elsewhere, to all of whom I owe many thanks.

\section{References}

1. M H Key, Nature 316, 314 (1985)

D L Matthews, R R Freeman (Eds) J Opt Soc Am 4, 533 (1987).

2. $\mathrm{K} M$ Gilbert, J Anthes, $M$ A Gusinov, H A Palmer, $R$ R Whitlock, P J Nagel, JAP 51, 1449 (1980).

3. D L Matthews et al, Phys Rev Lett $\underline{543}, 110$ (1985).

4. D L Matthews et a1, J Opt Soc Am 4, 575 (1987).

5. B J McGowan et a1, JAP 61, 5243 (1987).

6. T N Lee, E A Mclean, R L Elton, Phys Rev Lett 59, 1185 (1987).

7. B J McGowan, C J Keane, D L Matthews, UCRL Prepring 95971 (March 1987).

8. G J Pert, J Phys B 9, 3301 (1976), 12, 2067 (1979). M H Key, G J Pert, Rutherford Appleton Lab Annual Rep to Laser Facility Committee RAL 86-046, pA5.38 (1986).

9. I N Ross et al, Appl Opt 26, 1585 (1987).

10. G P Kiehn et al, Appl Opt 26, 425 (1987).

11. C Chenais-Popovics et al, Phys Rev Lett, Nov 1987 (in press).

12. M H Key, Rutherford Appleton Lab Annual Rep to the Laser Facility Committee RAL 87-041, 100 (1987).

13. O Willi et al, Proc SPIE Mutlilayer structures and laboratory X-ray laser research, 688, 2 (1987).

14. S Suckewer et al, Phys Rev Let 55, 1753 (1985) and 57, 1004 (1986).

15. P Jaeglé et al, J Opt Soc Am 4, 563 (1987). G Jamelot et al, J Phys B 18, 4647 (1985).

16. Reported by A Carrillon et al at 14th Int Conf on X-ray and Inner Shell Proesses, Paris September 1987.

17. A Carillon et a], Rutherford Appleton Lab Annual Rep to the Laser Facility Committee, RAI 87-041, B (1987).

18. Unpublished work at SERC Rutherford Appleton Lab in collaboration between UK groups and Univ Paris Orsay.

19. C M Brown et al JOSA 3, 701 (1986). and unpublished collaborative experiments at the SERC Rutherford Appleton Laboratory with J Seely, (NRL) and M Richardson (LLE).

20. D I Matthews, (private communication). 